\title{
Genetic Divergence and Diversity in Himalayan Puccinia striiformis Populations from Bhutan, Nepal, and Pakistan
}

\author{
Muhammad Rameez Khan, ${ }^{1}$ Zia-ur Rehman, ${ }^{1}$ Sidra Noreen Nazir, ${ }^{1}$ Sangay Tshewang, ${ }^{2}$ Suraj Baidya, ${ }^{3}$ David Hodson, ${ }^{4}$ \\ Muhammad Imtiaz, ${ }^{5}$ and Sajid Ali ${ }^{1, \dagger}$ \\ ${ }^{1}$ Institute of Biotechnology \& Genetic Engineering, The University of Agriculture, Peshawar, Pakistan \\ ${ }^{2}$ Department of Agriculture, Ministry of Agriculture and Forests, Tsirang, Bhutan \\ ${ }^{3}$ Plant Pathology Division, Nepal Agriculture Research Council, Nepal \\ ${ }^{4}$ International Maize and Wheat Improvement Center, CIMMYT, Mexico \\ 5 International Maize and Wheat Improvement Center, CIMMYT, Islamabad, Pakistan \\ Accepted for publication 7 June 2019.
}

ABSTRACT

\begin{abstract}
The western Himalayan region in Pakistan has been shown to be the center of diversity of Puccinia striiformis; however, little is known about its genetic relations with the eastern part of the Himalayas. We studied the genetic structure of $P$. striiformis from Nepal (35 isolates) and Bhutan (31 isolates) in comparison with 81 Pakistani samples collected during 2015 and 2016, through microsatellite genotyping. Genetic analyses revealed a recombinant and highly diverse population structure in Pakistan, Bhutan, and Nepal. A high level of genotypic diversity $(>0.90)$ was observed for the three countries of Pakistan (0.96), Bhutan (0.96), and Nepal (0.91) with the detection of 108 distinct multilocus genotypes (MLGs) in the overall population; 59 for Pakistan, 27 for Bhutan, and 26 for Nepal. Mean number of alleles per locus and gene diversity were higher in Nepal (3.19 and 0.458, respectively) than Bhutan (3.12 and 0.458, respectively). A nonsignificant difference between the observed and the expected heterozygosity in all populations further confirmed the recombinant
\end{abstract}

structure. A clear population subdivision between the Himalayan region of Nepal, Bhutan, and Pakistan was evident, as revealed by F $_{\mathrm{ST}}$ values (ranging between 0.111 to 0.198 ), discriminant analysis of principal components, and resampling of MLGs. Limited gene flow could be present between Nepal and Bhutan, while the population from Pakistan was clearly distinct, and no divergence was present between two populations from Pakistan (Bajaur and Malakand). The overall high diversity and recombination signature suggested the potential role of recombination in the eastern Himalayan region (Nepal and Bhutan), which needs to be considered during host resistance deployment and in the context of aerial dispersal of the pathogen. Further surveillance should be made in the Himalayan region for disease management in the region and in the context of worldwide invasions.

Keywords: diversity, divergence, population genetics, stripe rust, simple sequence repeat genotyping
Food security in developing countries is always challenging, where many factors affect the continuous and sufficient supply of food including devastating epidemics of diseases of food crops. Wheat, an important crop ensuring food security in many developing countries, is continuously facing environmental threats and disease risks. Among diseases, rust diseases particularly yellow rust (caused by Puccinia striiformis), pose severe threat to higher yield especially in the areas where the mild cold climate prevails during wheat cropping season (Chen 2005; Hovmøller et al. 2011). The pathogen survives better in areas where there are moist and cool weather conditions. The geographical range of $P$. striiformis is worldwide; it has occurred throughout recent history in Asia, Europe, and North Africa and in the early 1900s it was introduced into the Americas, and more recently into Australia and South Africa (Ali et al. 2014a; Beddow et al. 2015; Hodson 2011; Hovmøller et al. 2010). The

\section{${ }^{\dagger}$ Corresponding author: S. Ali; bioscientist122@yahoo.com}

Funding: The work was supported by the U.S. Department of Agriculture, Agricultural Research Service under agreement No. 58-0206-0-171 F; Wheat Productivity Enhancement Program (WPEP); Higher Education Commission, Pakistan Start-up Research Grant; the Delivering Genetic Gains in Wheat (DGGW) project supported by the Bill \& Melinda Gates Foundation, and the Department for International Development (DFID), UK.

*The $e$-Xtra logo stands for "electronic extra" and indicates that six supplementary figures and three supplementary tables are published online.

The author(s) declare no conflict of interest.

Copyright (C) 2019 The Author(s). This is an open access article distributed under the CC BY 4.0 International license. onset of disease on susceptible host in favorable environment leads to significant economic losses worldwide (Ali et al. 2017a).

To cope with the disease of wheat yellow rust, the use of chemicals has been suggested, which however, is not affordable to farmers of developing countries where the use of genetic resistance strategy is more fruitful and affordable (Ali et al. 2009; de Vallavieille-Pope et al. 2012; Paillard et al. 2012; Pathan and Park 2007). Genetic resistance is more economic, without any health and environment hazards (Chen 2005). Despite continuous efforts to develop resistant wheat varieties through incorporation of resistance genes, the effectiveness of these resistance genes remains limited due to acquisition of virulence by the pathogen population (de Vallavieille-Pope et al. 2012). More than 53 yellow rust resistance genes have been identified and many of these incorporated into wheat varieties (McIntosh et al. 2010). When resistant varieties, especially those with single major gene resistance, are deployed over large geographical regions there is high selection pressure for virulent variants of the pathogen. Virulent variants (either strains or lineages) of $P$. striiformis thus emerge to infect the resistant host varieties deployed over large areas.

Virulent strains could either evolve locally or through invasion from one location to another via wind or human-borne movement (Halkett et al. 2005; Hovmøller and Henriksen 2008; Hovmøller et al. 2002; Markell and Milus 2008; Wellings and McIntosh 1990). Local evolution occurs either through mutation or recombination. For recombination, rust fungi require both the primary and alternate hosts. The alternate hosts for yellow rust fungi are Berberis and Mahonia species (Jin et al. 2010; Rodriguez-Algaba et al. 2014). With sexual recombination on the alternate host, the pathogen can cope with adverse environmental conditions, provide inoculum to infect cereals every year, and generate new races resulting in overall 
diversification of the pathogen population (Taylor and Gurr 2014). Exotic incursions can also be a source of new variants. The pathogen is highly mobile, either through the movement of people, trade intensification, or aerial dispersal. P. striiformis has the capability to rapidly spread to new regions and crop varieties. For example, in 1979 wheat yellow rust was spread to Australia from Europe through human travel (O'Brien et al. 1980). The pathogen dispersal in the United Kingdom, Denmark, Germany, and France caused yellow rust on wheat varieties that were previously known to be resistant to the pathogen (Hovmøller et al. 2002). Thus, efforts for disease monitoring and control should be concentrated not only at the country level, but across the adjacent populations, which could serve as sources of invasions.

Recently, new emerging strains have been associated with worldwide wheat yellow rust epidemics (Ali et al. 2017a), including lineages aggressive at relatively warm climatic conditions (Hovmøller et al. 2008, 2016; Milus et al. 2009). A number of these lineages have been postulated to have originated in the nearHimalayan region (Hovmøller et al. 2016; Ali et al. 2017a). These near-Himalayan populations have been shown to be recombinant and highly diverse (Ali et al. 2014a, 2016; Thach et al. 2016), in contrast to the clonal population structure in the Americas, Europe, and Australia (Ali et al. 2014a). New variants arising in the Himalayan center of diversity can pose a threat to other wheat regions through aerial dispersal or human mediated transfer. Considering the importance of this pathogen dispersal threat, the population structure in the Himalayan regions of Pakistan, Nepal, and Bhutan needs to be studied and monitored in a worldwide context. Yellow rust has been, and continues to be, important in Pakistan, Nepal, and Bhutan (Bux et al. 2012; Mann and Hobbs 1988; Singh et al. 2004). However, the population structure of $P$. striiformis is unknown in Bhutan and limited information is available for Nepal, particularly in relation to the western Himalayan populations of Pakistan.

The present study was designed to understand $P$. striiformis population structure in the eastern Himalayan regions of Nepal and Bhutan along with the Pakistani Himalayan region based on samples collected in 2015 and 2016. The specific objectives of this study were to investigate diversity and signature of recombination presence of any population subdivision in $P$. striiformis populations from Pakistan, Nepal, and Bhutan, and to compare the population structure of Nepalese and Bhutanese Himalayan population with the Pakistani Himalayan population of $P$. striiformis.

\section{MATERIALS AND METHODS}

Sample collection and single lesion preparation. To describe the population structure of $P$. striiformis present

TABLE 1. Number of alleles, Simpson's diversity index, expected heterozygosity, and evenness calculated for 16 simple sequence repeat (SSR) loci in 66 Puccinia striiformis isolates sampled from Bhutan and Nepal

\begin{tabular}{lcccc}
\hline SSR locus & $\begin{array}{c}\text { Number of } \\
\text { alleles } \\
\text { detected }\end{array}$ & $\begin{array}{c}\text { Simpson's } \\
\text { diversity index } \\
(1-\mathrm{D})\end{array}$ & $\begin{array}{c}\text { Gene } \\
\text { diversity }\end{array}$ & Evenness \\
\hline RJO4 & 3 & 0.620 & 0.623 & 0.905 \\
RJO24 & 8 & 0.801 & 0.803 & 0.833 \\
RJN12 & 5 & 0.093 & 0.094 & 0.396 \\
RJN8 & 3 & 0.086 & 0.086 & 0.436 \\
RJN13 & 2 & 0.066 & 0.066 & 0.440 \\
RJN11 & 7 & 0.761 & 0.764 & 0.847 \\
RJN6 & 4 & 0.250 & 0.251 & 0.498 \\
RJO21 & 4 & 0.343 & 0.345 & 0.562 \\
RJN10 & 3 & 0.526 & 0.528 & 0.886 \\
RJO18 & 7 & 0.630 & 0.632 & 0.756 \\
WU6 & 5 & 0.195 & 0.196 & 0.435 \\
RJO20 & 4 & 0.548 & 0.550 & 0.785 \\
RJN4 & 4 & 0.554 & 0.556 & 0.854 \\
RJN9 & 4 & 0.029 & 0.029 & 0.311 \\
RJN5 & 5 & 0.622 & 0.624 & 0.774 \\
WU12 & 4 & 0.698 & 0.700 & 0.899 \\
\hline
\end{tabular}

in the Himalayan region of Nepal, Bhutan, and Pakistan, we collected a set of 147 samples from field infected wheat plants in 2015 and 2016 (Supplementary Fig. S1). This consisted of 81 single lesion samples from Pakistan (44 from Bajaur district and 37 from Malakand district), 31 from Bhutan, and 35 from Nepal (Supplementary Table S1). Single lesions were excised from these samples in situ for subsequent DNA extraction as described by Ali and Hodson (2017).

DNA extraction and microsatellite genotyping. DNA was extracted directly from single lesions (Ali et al. 2011a, b) using modified CTAB method (Ali et al. 2017b). The extracted DNA was amplified using 16 fluorescent simple sequence repeat (SSR) markers in two PCR multiplexes (Ali et al. 2017b). Fragment analysis of the amplified product was accomplished using the services of Uppsala University Genome Center through Aarhus University, Denmark. Fragment readings were carried out with GENEMARKER 4.05.2 software, reading each allele based on its allele size and formatted in MS Excel file (Ali et al. 2014b).

Population genetic analyses and interpretation. The suitability of markers to determine multilocus genotypes (MLGs) was assessed by plotting the number of MLGs detected versus the number of loci. GENETIX program was used for the estimation of $\mathrm{F}_{\mathrm{ST}}$ to measure population subdivision. Spatial population structure was further assessed using both model-based Bayesian and nonparametric multivariate clustering methods. Model-based Bayesian method implemented in the STRUCTURE 2.2 software (Pritchard et al. 2000) was used to assign MLGs into clusters with 20 independent runs, which were processed with CLUMPP (Jakobsson and Rosenberg 2007) to assign groups of runs to a common clustering pattern ( $\mathrm{G}$ '-statistic greater than $80 \%$ ). The optimal $\mathrm{K}$ value was determined using the method of Evanno et al. (2005) based on the rate of change in the log probability of data between successive $\mathrm{K}$ values. The results were further confirmed with discriminant analysis of principal components (DAPC) carried out in the ADEGENET package (Jombart et al. 2010). Phylogenetic tree was constructed using POPULATION software (Langella 2008) based on the genetic distances (Nei) between genotypes from the SSR dataset. Principal coordinate analysis of a Euclidean distance matrix was done in ADE4 package for both geographically spaced populations and STRUCTURE identified genetic groups.

The summary statistics were calculated using POPPR package within R-software. The summary statistics included number of different MLGs (showing genotypic richness); mean number of alleles and gene diversity (showing genetic diversity); Simpson's diversity index (showing genotypic diversity); evenness index (reflecting on relative distribution of genotypes abundance); and standardized index of association (rDbar) and its significance, showing linkage over loci. GENETIX 4.05.2 software (Belkhir et al. 2004) was used for the assessment of recombination signature by estimating the difference between the observed heterozygosity (Ho) and the expected heterozygosity (He).

\section{RESULTS}

Summary statistics of microsatellite markers. All 147 isolates of $P$. striiformis samples showed a varied level of polymorphism over the studied loci (Table 1). The number of alleles per locus ranged from two for RJN13 to eight for RJO24. The expected heterozygosity across loci was found to vary between 0.029 (RJN9) and 0.801 (RJO24). The evenness across loci ranged from 0.311 (RJN9) to 0.905 (RJO4). The tested markers were enough to capture the maximum diversity in the population as revealed by plotting the identified MLGs against the number of loci (Supplementary Fig. S2). Increasing the number of loci resulted in increasing the capacity of markers to capture the MLGs. The maximum number of MLGs (108) were already captured by 13 loci, reaching the maximum distribution around 108 MLGs at 16 loci. 
Genetic diversity and recombination signature. High diversity and a recombinant population structure were observed in the $P$. striiformis populations from Nepal, Bhutan, and Pakistan as assessed through estimation of the expected heterozygosity and allele richness. There was a nonsignificant difference between the expected heterozygosity $(\mathrm{He})$ and observed heterozygosity $(\mathrm{Ho})$ for Nepalese, Bhutanese, and Pakistani (Malakand and Bajaur) $P$. striiformis populations suggesting recombination in all studied locations (Fig. 1). Gene diversity in the overall population was found to be 0.428 . Gene diversity was higher in Nepalese population (0.458) followed by Malakand (0.368), Bajaur (0.348), and Bhutanese population (0.344). Overall, a high genotypic diversity was observed in all populations as revealed by Simpson's index ( 0.957 for Bhutan and Malakand; Table 2) compared with the clonal populations in Europe where the diversity within the crop season was less than 0.50 (Ali et al. 2014a; Thach et al. 2016). The high diversity was further affirmed by the 108 distinct MLGs (out of 147 samples) detected in the overall population, out of which 27 were detected in Bhutan, 26 in Nepal, 29 in Bajaur, and 30 in Malakand regions from Pakistan (Table 2).

Population subdivision in the Himalayan population. The principle coordinate analysis revealed three groups, one specific to Bhutan, another one in Nepal, and the third one predominantly present in Pakistan, with some resampling in Bhutan and Nepal and little in Pakistan as well (Fig. 2A). This population subdivision was further confirmed by a highly significant $(P<0.001)$ and strong $F_{\mathrm{ST}}$ value of geographically different populations ranging from 0.196 to 0.168 , while the $\mathrm{F}_{\mathrm{ST}}$ among Bajaur and Malakand was estimated to be 0.032 (Table 3 ). Neighbor joining tree and network analyses further confirmed the population subdivision across countries, where samples from Bhutan were relatively closer to the Nepalese, with limited closeness to Pakistani samples (Fig. $2 \mathrm{~B}$ and $\mathrm{C}$ ).

To identify genetic clusters in the tested populations and assignment of samples into these clusters, the model-based STRUCTURE and DAPC analyses suggested the existence of at least four clusters

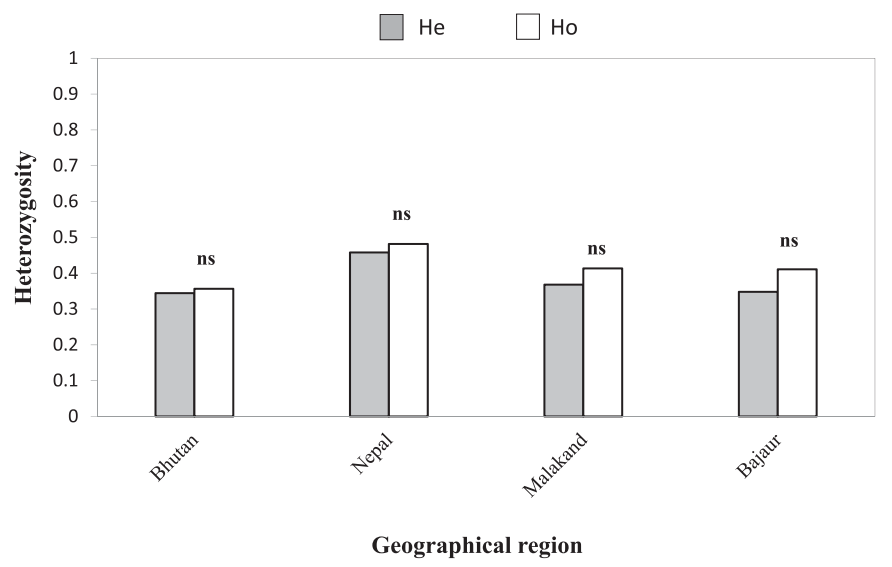

Fig. 1. Observed $(\mathrm{Ho})$ and unbiased expected $(\mathrm{He})$ heterozygosity over 16 microsatellite markers for Puccinia striiformis populations sampled in Bhutan, Nepal, and Pakistan (Bajaur and Malakand). in the data (Supplementary Fig. S3), which were quite distant from each other when plotted over a scatter plot (Fig. 3; Supplementary Fig. S4). Assignment of isolates into these clusters revealed that one cluster was specific to Bhutan only (G4) with limited admixture in Pakistan, while one cluster (G3) was predominant in Nepal but resampled in Pakistan and Bhutan as well. G1 was predominant in Pakistan, though with limited admixture in Bhutan as well (Fig. 3). G2 was specific to the eastern Himalayas, present only in Bhutan and Nepal, and absent in Pakistan. An overall high diversity and signature of recombination was observed within each genetic group identified with STRUCTURE (Table 4) and DAPC (Supplementary Table S3).

We assessed the placement of worldwide predominant linages (PstS0 till PstS10; Ali et al. 2017a) in comparison with these Himalayan population through making a neighbor-joining tree based on comparison of SSR profile of these worldwide linages (available from Ali et al. 2017a). The lineages PstS6, PstS7, and PstS9 were placed within the Himalayan populations, as reported in the worldwide study as well (Ali et al. 2017a). The rest emerged as separate linages (Fig. 4).

Resampling of MLGs and their spatial distribution. Resampling of MLGs at the same location or across different geographically spaced populations reflected the presence of low clonality and very limited migration of clones from one region to the other. A limited number of MLGs were resampled two or more than two times. None of the MLGs were found to be present across all the geographically spaced populations. Out of 108 distinct MLGs, only 15 were resampled. Only two MLGs were resampled between Nepal and Bhutan, i.e., MLG-71 was resampled 12 times (nine times in Nepal and three times in Bhutan) and MLG-81 sampled once in Nepal and once in Bhutan. None of the MLGs were shared between Pakistan and either Nepal or Bhutan. In Pakistan, MLG-51 and MLG-52 were resampled six times in Bajaur only. Similarly, three MLGs were resampled four times and nine MLGs were resampled only twice at the same or different location (Table 5). This is further evidenced from the haplotype network analyses (Fig. 2C).

\section{DISCUSSION}

This study describes the genetic structure of the $P$. striiformis population in the Himalayan region of Pakistan, Nepal, and Bhutan. Based on a set of 147 field samples ( 35 from Nepal, 31 from Bhutan, and 81 from Pakistan) from 2015 to 2016 . Microsatellite genotyping and subsequent population genetics analyses revealed a high diversity and recombinant population structure in the eastern Himalayan region with limited migration across countries. Results would support recent research indicating the Himalayan region as a center of diversity for $P$. striiformis (Ali et al. 2014a).

Recombination signals and high genetic diversity in both eastern and western Himalayas. High genetic diversity and strong signal of recombinant population structure was evident in the eastern Himalaya region (Nepal and Bhutan) and in the western Himalayan region (Pakistan). High values of diversity indices, low linkage disequilibrium and lack of difference between expected and observed heterozygosity supported this proposition. Previously, the

TABLE 2. Diversity parameters in Puccinia striiformis populations sampled in the Himalayan region of Bhutan, Nepal, and Pakistan (Bajaur and Malakand)

\begin{tabular}{|c|c|c|c|c|c|}
\hline Diversity parameters & Bhutan & Nepal & Bajaur & Malakand & Overall population \\
\hline Sample size & 31 & 35 & 44 & 37 & 147 \\
\hline Number of different multilocus genotypes & 27 & 26 & 29 & 30 & 108 \\
\hline Mean number of alleles & 3.125 & 3.188 & 3.500 & 2.688 & 3.125 \\
\hline Simpson's diversity index & 0.957 & 0.911 & 0.940 & 0.957 & 0.982 \\
\hline Evenness index & 0.916 & 0.565 & 0.720 & 0.853 & 0.642 \\
\hline Gene diversity & 0.344 & 0.458 & 0.348 & 0.368 & 0.428 \\
\hline Standardized index of association (rDbar) & 0.132 & 0.273 & 0.198 & 0.088 & 0.132 \\
\hline$P$ value for rDbar & 0.001 & 0.001 & 0.001 & 0.001 & 0.001 \\
\hline
\end{tabular}



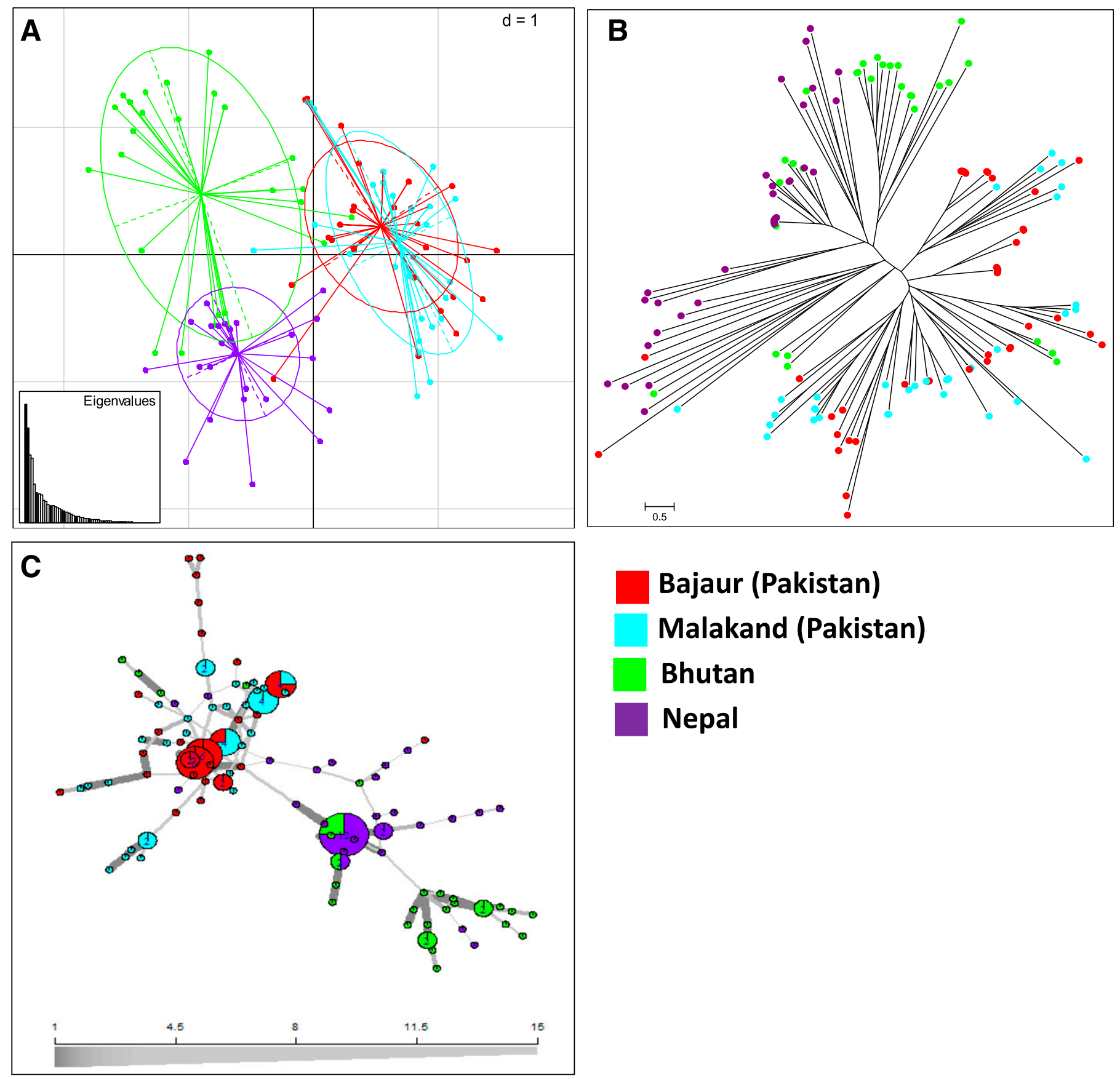

Fig. 2. Relationship of Himalayan Puccinia striiformis populations from Bhutan, Nepal, and Pakistan (Bajaur and Malakand) based on 16 microsatellite genotype data as revealed through $\mathbf{A}$, principal coordinate analysis, $\mathbf{B}$, neighbor-joining tree, and $\mathbf{C}$, network analyses.

TABLE 3. Divergence (in terms of $\mathrm{F}_{\mathrm{ST}}$ values, upper diagonal and its significance, the lower diagonal) among the geographical spaced populations and

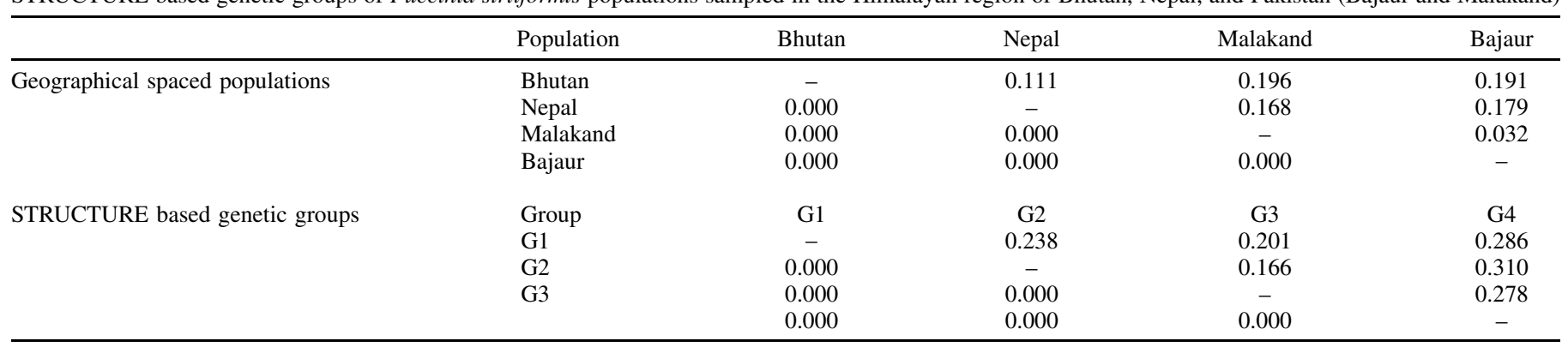



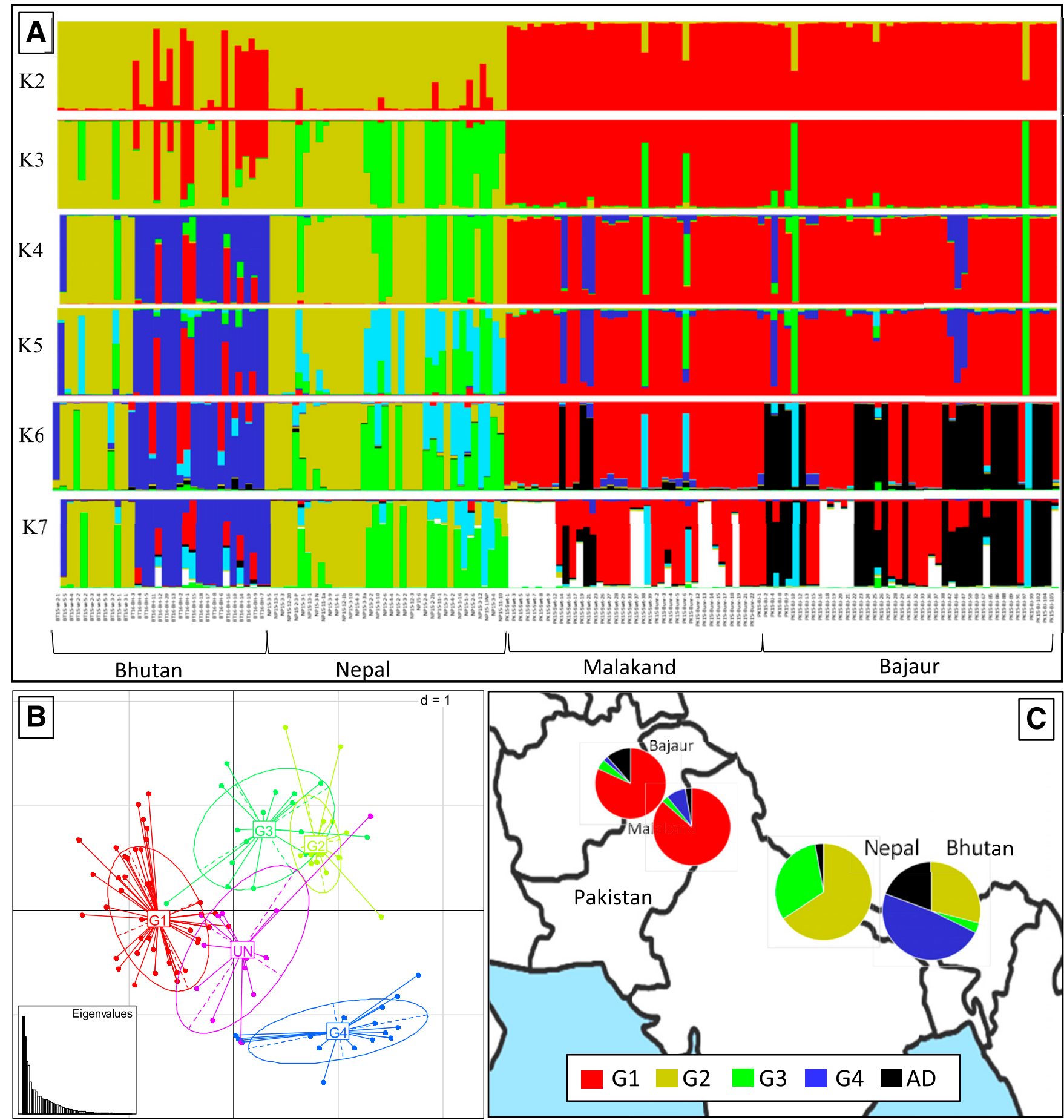

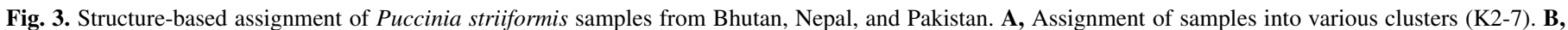
Scatter plot of the clusters identified at $\mathrm{K}=4$. C, Distribution of the four clusters and admixed group across the Himalayan populations.

TABLE 4. Diversity parameters for genetic groups identified through STRUCTURE software in the Puccinia striiformis populations from the Himalayan region of Bhutan, Nepal, and Pakistan

\begin{tabular}{|c|c|c|c|c|c|}
\hline Diversity parameters & G1 & G2 & G3 & G4 & Admixed \\
\hline Sample size & 68 & 31 & 16 & 19 & 13 \\
\hline Number of different multilocus genotypes & 44 & 18 & 16 & 17 & 13 \\
\hline Mean number of alleles & 2.625 & 2.125 & 3.937 & 2.062 & 3.000 \\
\hline Evenness index & 0.751 & 0.483 & 1.000 & 0.953 & 1.000 \\
\hline Gene diversity & 0.119 & 0.240 & 0.049 & 0.103 & 0.106 \\
\hline Standardized index of association (rDbar) & 0.060 & 0.140 & 0.049 & 0.099 & 0.106 \\
\hline$P$ value for $\mathrm{rDbar}$ & 0.001 & 0.001 & 0.001 & 0.001 & 0.001 \\
\hline
\end{tabular}


Himalayan and near-Himalayan regions including Pakistan, Nepal, and China were reported to be the center of origin and diversity for P. striiformis (Ali et al. 2014a), where the pathogen was postulated to undergo sexual reproduction on Berberis spp. (Ali et al. 2014b; Jin et al. 2010; Ray et al. 2011). Similarly, the ancestral relationship also confirmed the Himalayan population to be the ancestral population (Ali et al. 2014a). The observed high genetic diversity was in contrast to other areas of the world, where the genetic variability of $P$. striiformis population was found to be very low (Ali 2012; Ali et al. 2014a). A clonal population structure was observed in United States (Chen 2005), Australia (Thach et al. 2016), and Europe (Ali et al. 2014a; de Vallavieille-Pope et al. 2012; Thach et al. 2016). Observed genetic diversity was also higher than the Middle Eastern and Mediterranean populations (Ali et al. 2014a; Bahri et al. 2009).

The observed high genotypic diversity would also imply high adaptation capacity of the pathogen to acquire diverse virulence profiles and adapt to diverse environmental conditions (Ali et al. 2010; Jin et al. 2010). A high diversity in virulence and pathotype was previously observed in recombinant populations of Pakistan (Ali et al. 2014c; Ali et al. 2017a). Little was known about the virulence and phenotype structure of $P$. striiformis in Nepal, with only a recent study showing low pathotype diversity with high genetic diversity (Ali et al. 2018). No published study on the Bhutanese $P$. striiformis population and the relationship between these Himalayan populations is available to date, whereas only a limited number of $P$. striiformis samples from Bhutan have been pathotyped (Ali et al. 2017a). Initial results indicated potential diversity. Hovmøller et al. (2016) reported six races from 10 isolates. Considering the high genetic diversity in both Nepal and Bhutan, expanded analysis on virulence and pathotypes must be made in these regions. Populations containing more variations in alleles could provide variation suited to the environment into which they are migrating, thus enabling successful invasions from the diverse populations (Hovmøller et al. 2016).

Population subdivision and migrations within Himalayan $\boldsymbol{P}$. striiformis populations. Analysis revealed a clear population subdivision between the Himalayan region of Nepal, Bhutan, and Pakistan, as revealed by $\mathrm{F}_{\mathrm{ST}}$ values, DAPC analyses, and resampling of MLGs. Though a very limited gene flow could be present between Nepal and Bhutan, the population from Pakistan was clearly distinct. Samples representing various genetic groups in a country may have different adaptation to host resistance and may pose a threat if migration occurs from one lineage prevalent region

TABLE 5. Distribution of distinct multilocus genotypes (MLGs) detected in Puccinia striiformis populations sampled in the Himalayan region of Bhutan, Nepal, and Pakistan (Bajaur and Malakand)

\begin{tabular}{lccccc}
\hline MLG & Bhutan & Nepal & Malakand & Bajaur & $\begin{array}{c}\text { Overall } \\
\text { population }\end{array}$ \\
\hline MLG-71 & 3 & 9 & - & - & 12 \\
MLG-51 & - & - & - & 6 & 6 \\
MLG-52 & - & - & - & 6 & 6 \\
MLG-40 & - & - & 4 & - & 4 \\
MLG-41 & - & - & 1 & 3 & 4 \\
MLG-42 & - & - & 3 & 1 & 4 \\
MLG-102 & 2 & - & - & - & 2 \\
MLG-103 & 2 & - & - & - & 2 \\
MLG-24 & - & - & 2 & - & 2 \\
MLG-50 & - & - & - & 2 & 2 \\
MLG-53 & - & - & - & 2 & 2 \\
MLG-6 & - & - & 2 & - & 2 \\
MLG-67 & - & 2 & - & - & 2 \\
MLG-81 & 1 & 1 & - & - & 2 \\
MLG-95 & - & - & - & 2 & 2 \\
Number of single MLGs & 23 & 23 & 25 & 22 & 93 \\
Sample size & 31 & 35 & 37 & 44 & 147
\end{tabular}

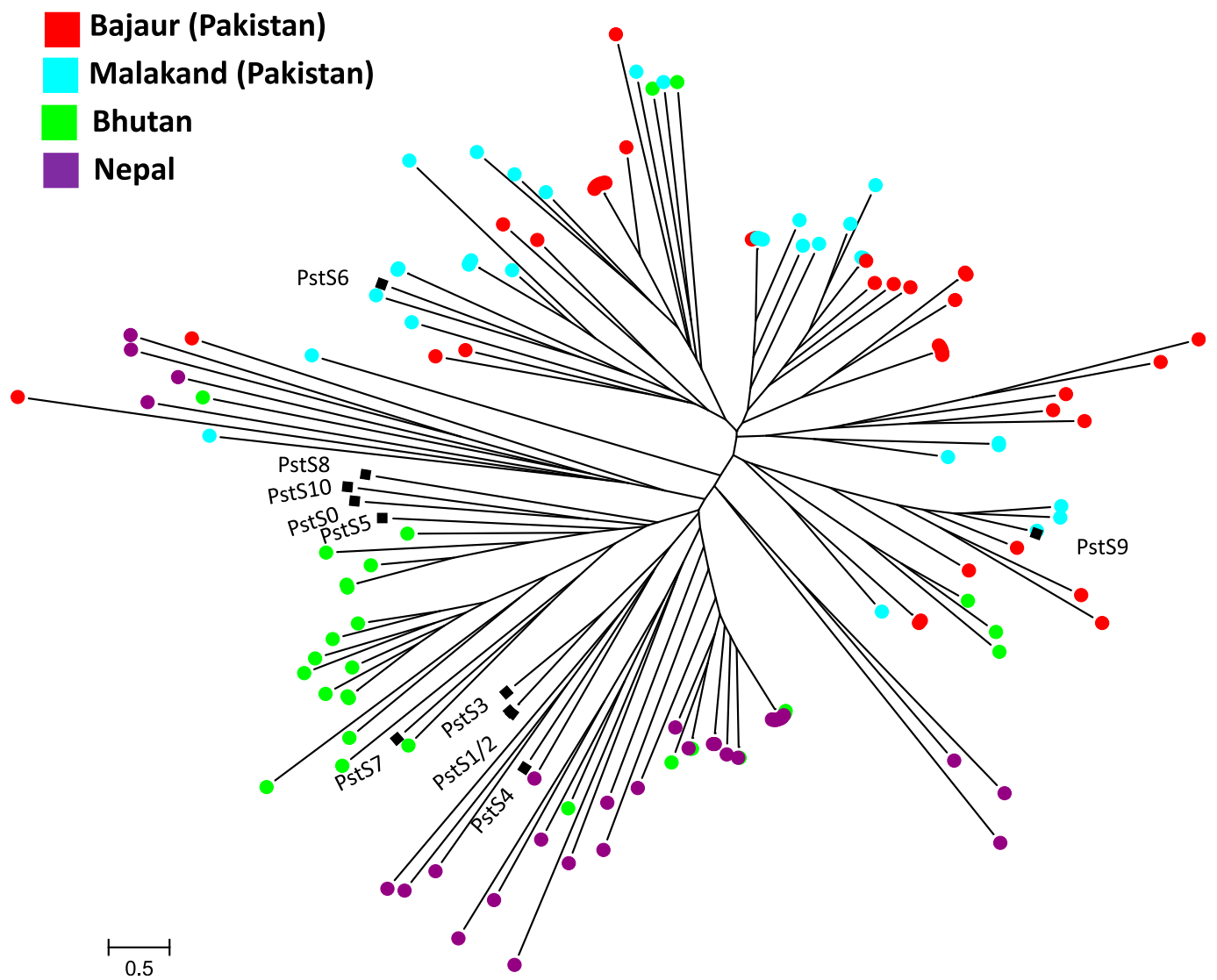

Fig. 4. Placement of worldwide predominant linages (PstS0 till PstS10; Ali et al. 2017a) in comparison with these Himalayan populations through a neighborjoining tree based on comparison of simple sequence repeat profiles of these worldwide linages (available from Ali et al. 2017a). 
to another (Hovmøller et al. 2016; Walter et al. 2016). P. striiformis is well known for its long-distance migration capacity through wind dispersal (Brown and Hovmøller 2002), and thus a limited gene flow over the region could still be possible. Thus, the existence of overall population subdivision could be explained by the local maintenance of the population with a potential role of recombination in each country (Ali et al. 2016) isolated by high mountainous ranges. Finally, the wheat varieties grown in the region are predominantly CIMMYT-based varieties (Lantican et al. 2016), which are often genetically related across the region and include identical varieties released in multiple countries (Ali et al. 2014c; Singh et al. 2004). Indeed, the role of host selection has been limited in the Himalayan region, where multiple linages can infect the same variety (Khan and Ali 2018) and the same pathotype can be represented by distinct MLGs (Ali et al. 2017a, 2018).

Implication for worldwide yellow rust management. Yellow rust is expanding its range globally (Beddow et al. 2015) with both wind-borne and human-mediated transport by important dispersal mechanisms (Brown and Hovmøller 2002; O'Brien et al. 1980). Recent, long-distance exotic incursions, e.g., the 'Warrior' (PstS7) race into Western Europe (Hovmøller et al. 2016) and race PstS11 from Afghanistan into East Africa (Hovmøller et al. 2018), highlight the importance of the Himalayan/near-Himalayan region as a source of new virulence profiles that result in damaging consequences in distant regions. Invasive strains originating in diverse populations could have advantage over the existing pathogen populations if they harbor novel virulence factors and/ or adaptation to new climatic conditions (Walter et al. 2016). It could also be due to increased aggressiveness of the invasive strains on the hosts, which were considered to be resistant to the prevailing pathogen populations (Hovmøller et al. 2016). Invasive strains with novel virulence profiles, adaptation to new climatic conditions, or increased aggressiveness can rapidly replace prevailing pathogen populations, resulting in damaging epidemics over large geographical regions (Ali et al. 2017a; Walter et al. 2016). Results of this study highlight the critical need for expanded monitoring and understanding of populations in the Himalayan region, coupled to improving collaborative efforts to manage yellow rust at the national, regional, and global scale.

Conclusion. Our study revealed a strong signal for a recombinant population structure in Pakistan, Bhutan, and Nepal with very high genetic diversity, but limited migration across the countries. The results imply that there are most likely multiple sources of $P$. striiformis variation occurring within the Himalayan region. Given the high dispersal capacity of $P$. striiformis, these sources of new variation and diversity have global importance. Previously, invasive strains of $P$. striiformis introduced into new regions has resulted in huge epidemics across large geographical regions. To avoid such surprises and emergency situations, collaborative efforts has strongly been suggested to tackle the disease at the national, regional, and worldwide scale (Ali et al. 2017a).

\section{ACKNOWLEDGMENTS}

We also acknowledge the support of S. Nawab, S. Dorji, and Tshumo during the sampling.

\section{LITERATURE CITED}

Ali, S. 2012. Population biology and invasion history of Puccinia striiformis $\mathrm{f}$. sp. tritici at worldwide and local scale (Thèse de doctorat, Université Paris Sud (Paris 11), FRA). https://prodinra.inra.fr/record/178600

Ali, S., Enjalbert, J., Leconte, P., Gautier, A., Hovmøller, M. S., and de Vallvieille-Pope, C. 2011a. Asian populations of the wheat stripe rust pathogen as a potential source of new emergences, due to their high genotypic and phenotypic diversity. In XVI Congress of European Mycologists, Halkidiki, Greece.

Ali, S., Gautier, A., Leconte, M., Enjalbert, J., and de Vallavieille-Pope, C. 2011b. A rapid genotyping method for an obligate fungal pathogen,
Puccinia striiformis f. sp. tritici, based on DNA extraction from infected leaf and multiplex PCR genotyping. BMC Res. Notes 4:240.

Ali, S., Gladieux, P., Leconte, M., Gautier, A., Justesen, A. F., Hovmoller, M. S., Enjalbert, J., and de Vallavieille-Pope, C. 2014a. Origin, migration routes and worldwide population genetic structure of the wheat yellow rust pathogen Puccinia striiformis f. sp. tritici. PLoS Pathog 10:e1003903.

Ali, S., Gladieux, P., Rahman, H., Saqib, M. S., Fiaz, M., Ahmed, H., Leconte, M., Gautier, A., Justesen, A. F., Hovmøller, M. S., Enjalbert, J., and de Vallavieille-Pope, C. 2014b. Inferring the contribution of sexual reproduction, migration and off-season survival to the temporal maintenance of microbial populations: A case study on the wheat fungal pathogen Puccinia striiformis f. sp. tritici. Mol. Ecol. 23:603-617.

Ali, S., and Hodson, D. 2017. Wheat rust surveillance; field disease scoring and sample collection for phenotyping and molecular genotyping. Pages 3-11 in: Methods in Molecular Biology, vol. 1659. S Periyannan, ed. Humana Press, New York.

Ali, S., Khan, M. R., Gautier, A., Swati, Z. A., and Walter, S. $2017 \mathrm{~b}$. Microsatellite genotyping of the wheat yellow rust pathogen Puccinia striiformis. Page 445 in: Wheat Rust Disease-Methods in Molecular Biology. S. Periyannan, ed. Humana Press, New York.

Ali, S., Leconte, M., Rahman, H., Saqib, M. S., Gladieux, P., Enjalbert, J., and de Vallavieille-Pope, C. 2014c. A high virulence and pathotype diversity of Puccinia striiformis f. sp. tritici at its centre of diversity, the Himalayan region of Pakistan. Eur. J. Plant Pathol. 140:275-290.

Ali, S., Leconte, M., Walker, A. S., Enjalbert, J., and de Vallavieille-Pope, C. 2010. Reduction in the sex ability of worldwide clonal populations of Puccinia striiformis f. sp. tritici. Fungal Genet. Biol. 47:828-838.

Ali, S., Rahman, H., Shah, S. J. A., Ali Shah, S. M., and Farhatullah. 2009. Assessment of field resistance using host-pathogen interaction phenotype for wheat yellow rust. Afr. Crop Sci. J. 17:213-221.

Ali, S., Sharma, S., Leconte, M., Shah, S. J. A., Duveiller, E., and de Vallvieille-Pope, C. 2018. Low pathotype diversity in a recombinant Puccinia striiformis population through convergent selection at the Eastern part of Himalayan centre of diversity (Nepal). Plant Pathol. 67:810-820.

Ali, S., Rodriguez-Algaba, J., Thach, T., Sørensen, C., Hansen, J. G., Lassen, P., et al. 2017a. Yellow rust epidemics worldwide were caused by pathogen races from divergent genetic lineages. Front. Plant Sci. 8:1057.

Ali, S., Soubeyrand, S., Gladieux, P., Giraud, T., Leconte, M., Gautier, A., Mboup, M., de Vallavieille-Pope, C., and Enjalbert, J. 2016. CloNcaSe: Estimation of sex frequency and effective population size by clonemate resampling in partially clonal organisms. Mol. Ecol. Resour. 16:213-303.

Bahri, B., Leconte, M., Ouffroukh, A., Vallavieille-Pope, D., and Enjalbert, J. 2009. Geographical limits of a clonal population of wheat yellow rust in the Mediterranean region. Mol. Ecol. 18:4165-4179.

Beddow, J. M., Pardey, P. G., Chai, Y., Hurley, T. M., Kriticos, D. J., Braun, J. C., Park, R. F., Cuddy, W. S., and Yonow, T. 2015. Research investment implications of shifts in the global geography of wheat stripe rust. Nature Plants 1:15132.

Belkhir, K. B. P., Chikhi, L., Raufaste, N., and Bonhomme, F. 2004. GENETIX 4.05, logiciel sous Windows TM pour la genetique des populations. Laboratoire Genome, Populations, Interactions, Universite de Montpellier II, Montpellier, France.

Brown, J. K. M., and Hovmøller, M. S. 2002. Aerial dispersal of fungi on the global and continental scales and its consequences for plant disease. Science 297:537-541.

Bux, H., Rasheed, A., Mangrio, S. M., Abro, S. A., Shah, S. J. A., Ashraf, M., and Chen, X. 2012. Comparative virulence and molecular diversity of stripe rust (Puccinia striiformis f. sp. tritici) collections from Pakistan and United States. Int. J. Agric. Biol. 14:851-860.

Chen, X. M. 2005. Epidemiology and control of stripe rust [Puccinia striiformis f. sp. tritici] on wheat. Can. J. Plant Pathol. 27:314-337.

de Vallavieille-Pope, C., Ali, S., Leconte, M., Enjalbert, J., Delos, M., and Rouzet, J. 2012. Virulence dynamics and regional structuring of Puccinia striiformis f. sp. tritici in France between 1984 and 2009. Plant Dis. 96: 131-140.

Evanno, G., Regnaut, S., and Goudet, J. 2005. Detecting the number of clusters of individuals using the software STRUCTURE: A simulation study. Mol. Ecol. 14:2611-2620.

Halkett, F., Simon, J., and Balloux, F. 2005. Tackling the population genetics of clonal and partially clonal organisms. Trends Ecol. Evol. 20:194-201.

Hodson, D. P. 2011. Shifting boundaries: Challenges for rust monitoring. Euphytica 179:93-104.

Hovmøller, M. S., and Henriksen, K. E. 2008. Application of pathogen surveys, disease nurseries and varietal resistance characteristics in an IPM approach for the control of wheat yellow rust. Eur. J. Plant Pathol. 121: 377-385.

Hovmøller, M. S., Justesen, A. F., and Brown, J. K. M. 2002. Clonality and long-distance migration of Puccinia striiformis f. sp. tritici in north-west Europe. Plant Pathol. 51:24-32. 
Hovmøller, M. S., Rodreguez-Algaba, J., and Hansen, J. G. 2018. Report for Puccinia striiformis race analyses 2015, Global Rust Reference Center (GRRC). Aarhus University, Denmark. http://wheatrust.org/fileadmin/ www.grcc.au.dk/International_Services/Pathotype_YR_results/Summary_ of_Puccinia_striiformis_race_analysis_2015.pdf

Hovmøller, M. S., Walter, S., Bayles, R., Hubbard, A., Flath, K., Sommerfeldt, N., Leconte, M., Rodriguez-Algaba, J., Hansen, J. G., Lassen, P., Justesen, A. F., Ali, S., and de Vallavieille-Pope, C. 2016. Replacement of the European wheat yellow rust population by new races from the centre of diversity in the near-Himalayan region. Plant Pathol. 65:402-411.

Hovmøller, M. S., Sørensen, C. K., Walter, S., and Justesen, A. F. 2011. Diversity of Puccinia striiformis on cereals and grasses. Annu. Rev. Phytopathol. 49:197-217.

Hovmøller, M. S., Walter, S., and Justesen, A. F. 2010. Escalating threat of wheat rusts. Science 329:369.

Hovmøller, M. S., Yahyaoui, A. H., Milus, E. A., and Justesen, A. F. 2008. Rapid global spread of two aggressive strains of a wheat rust fungus. Mol. Ecol. 17:3818-3826.

Jakobsson, M., and Rosenberg, N. A. 2007. CLUMPP: A cluster matching and permutation program for dealing with label switching and multimodality in analysis of population structure. Bioinformatics 23:1801-1806.

Jin, Y., Szabo, L. J., and Carson, M. 2010. Century-old mystery of Puccinia striiformis life history solved with the identification of Berberis as an alternate host. Phytopathology 100:432-435.

Jombart, T., Devillard, S., and Balloux, F. 2010. Discriminant analysis of principal components: A new method for the analysis of genetically structured populations. BMC Genet. 11:94.

Khan, M. R., and Ali, S. 2018. Population structure of wheat rust pathogen in Pakistan and its temporal maintenance over time. Ph.D. thesis. Institute of Biotechnology \& Genetic Engineering, the University of Agriculture, Peshawar, Pakistan

Langella, O. 2008.POPULATIONS 1.2.3, Logiciel de génétique des populations, Laboratoire Populations, Génétique et évolution, CNRS, 91190 Gif-sur-Yvette, France.

Lantican, M. A., Braun, H. J., Payne, T. S., Singh, R. P., Sonder, K., Baum, M., van Ginkel, M., and Erenstein, O. 2016. Impacts of International Wheat Improvement Research, 1994-2014. CIMMYT, Mexico.

Mann, C. E., and Hobbs, P. R. 1988. Wheat and wheat development in Bhutan. CIMMYT, Mexico.

Markell, S. G., and Milus, E. A. 2008. Emergence of a novel population of Puccinia striiformis f. sp. tritici in eastern United States. Phytopathology 98:632-639.
McIntosh, R. A., Dubcovsky, J., and Rogers, W. J. 2010. Catalogue of gene symbols. KOMUGI Integr. Wheat Sci. Database 68:19-53.

Milus, E. A., Kristensen, K., and Hovmøller, M. S. 2009. Evidence for increased aggressiveness in a recent widespread strain of Puccinia striiformis f. sp. tritici causing stripe rust of wheat. Phytopathology 99:89-94.

O'Brien, L., Brown, J. S., Young, R. M., and Pascoe, I. 1980. Occurrence and distribution of wheat stripe rust in Victoria and susceptibility of commercial wheat cultivars. Australasian Plant Pathol. 9:14.

Paillard, S., Trotoux-Verplancke, G., Perretant, M. R., Mohamadi, F., Leconte, M., Coëdel, S., de Vallavieille-Pope, C., and Dedryver, F. 2012. Durable resistance to stripe rust is due to three specific resistance genes in French bread wheat cultivar Apache. Theor. Appl. Genet. 125:955-965.

Pathan, A. K., and Park, R. F. 2007. Evaluation of seedling and adult plant resistance to stem rust in European wheat cultivars. Euphytica 155: 87-105.

Pritchard, J. K., Stephens, M., and Donnelly, P. 2000. Inference of population structure using multilocus genotype data. Genetics 155:945-959.

Ray, R., Gururaja, K. V., and Ramchandra, T. V. 2011. Predictive distribution modeling for rare Himalayan medicinal plant Berberis aristata DC. J. Environ. Biol. 32:725-730.

Rodriguez-Algaba, J., Walter, S., Sørensen, C. K., Hovmøller, M. S., and Justesen, A. F. 2014. Sexual structures and recombination of the wheat rust fungus Puccinia striiformis on Berberis vulgaris. Fungal Genet. Biol. 70: 77-85.

Singh, R. P., William, H. M., Huerta-Espino, J., and Rosewarne, G. 2004. Wheat rust in Asia: Meeting the challenges with old and new technologies. Pages 6-641 in: Proceedings of the 4th International Crop Science Congress, Brisbane, Australia.

Taylor, C., and Gurr, S. 2014. Fungal pathogenesis: Past, present and future. Fungal Biol. Rev. 28:24-28.

Thach, T., Ali, S., de Vallavieille-Pope, C., Justesen, A. F., and Hovmøller, M. S. 2016. Worldwide population structure of the wheat rust fungus Puccinia striiformis in the past. Fungal Genet. Biol. 87:1-8.

Walter, S., Ali, S., Kemen, E., Nazari, K., Bahri, B. A., Enjalbert, J., Hanson, J. G., Brown, J. K. M., Ponten, T. S., Jones, J., Vallavieille-Pope, V., Hovmoller, M. S., and Justesen, A. F. 2016. Molecular markers for tracking the origin and worldwide distribution of invasive strains of Puccinia striiformis. Ecol. Evol. 6:2790-2804.

Wellings, C. R., and McIntosh, R. A. 1990. Puccinia striiformis f. sp. tritici in Australia: Pathogenic changes during the first 10 years. Plant Pathol. 39: 316-325. 